\title{
The effect of chlorhexidine on plaque index and mutans streptococci in orthodontic patients: A pilot study
}

\author{
Gisele Faria ${ }^{1}$, Milton Santamaria Jr. ${ }^{2}$, Bianca Mota dos Santos ${ }^{3}$, Izabel Yoko Ito $^{4}$, \\ Janete Cinira Bregagnolo ${ }^{2}$, Maria Bernadete Sasso Stuani ${ }^{2 *}$ \\ ${ }^{1}$ Department of Restorative Dentistry, School of Dentistry of Araraquara, University of the State of São Paulo (UNESP), Araraquara, \\ Brazil \\ ${ }^{2}$ Department of Pediatric Clinics, Preventive and Social Dentistry, School of Dentistry of Ribeirao Preto, University of São Paulo \\ (USP), Ribeirão Preto, Brazil \\ ${ }^{3}$ Private Practice, Aracaju, Brazil \\ ${ }^{4}$ Department of Clinical Analysis, Toxicology and Bromatology, School of Pharmaceutical Sciences of Ribeirao Preto, University of \\ São Paulo (USP), Ribeirão Preto, Brazil \\ Email: "bernadete@forp.usp.br
}

Received 17 February 2013; revised 18 March 2013; accepted 17 April 2013

Copyright (C) 2013 Gisele Faria et al. This is an open access article distributed under the Creative Commons Attribution License, which permits unrestricted use, distribution, and reproduction in any medium, provided the original work is properly cited.

\begin{abstract}
Aim: The purpose of this study was to assess chlorhexidine effects on plaque index and salivary levels of mutans streptococci (MS) when used as the immersion solution for removable orthodontic appliances and added to their acrylic resin composition. Methods: Forty-five patients (6 to 12 years old) were randomly assigned into three groups with 15 patients each. Group I (control)-without orthodontic appliances disinfection; Group II-removable orthodontic appliances which had been immersed in $0.12 \%$ chlorhexidine digluconate overnight (8 hours), and Group III-orthodontic appliances in which $0.12 \%$ chlorhexidine digluconate solution had been incorporated into their resin composition. Saliva was collected for quantification of MS and evaluation of plaque index was performed before and after installation of orthodontic appliance at $0,2,4,6,8$, and 10 weeks. Data were analyzed by using analysis of variance. Results: Number of MS colonies in saliva and plaque index showed no statistically differences among groups at the different periods $(p>0.05)$. Conclusions: It could be concluded that chlorhexidine incorporation into the acrylic resin of removable orthodontic appliances at $0.12 \%$ concentration and immersion of the appliance into $0.12 \%$ chlorhexidine solution were not effective in reducing plaque index and the number of MS in saliva.
\end{abstract}

Keywords: Chlorhexidine; Self-Polymerising Acrylic;

\footnotetext{
"Corresponding author.
}

Removable Orthodontic Appliances; Mutans

Streptococci; Plaque Index

\section{INTRODUCTION}

The insertion of orthodontic appliances results in a number of new retention sites which favor local adherence and growth of mutans streptococci (MS) [1-3]. These microorganisms can promote biofilm formation on brackets [4,5], orthodontic wires [6], elastics [7], and acrylic resin [8-10]. Results of studies have shown that placement of fixed orthodontic appliance can alter the oral microbiota, increasing plaque volume and levels of MS in saliva [2,5,11-13]. The increased levels of MS may subsequently become a factor favouring the higher incidence of enamel demineralization seen in some patients with fixed orthodontic appliances [14]. This stresses the need of preventive strategies during the treatment period, for example, use of antimicrobial agents [1] to aid in the control of bacterial colonization because toothbrushes cannot completely remove microorganisms from critical retentive sites of the fixed orthodontic appliances [6].

Some disinfectants such as cetylpyridinium chloride, sodium hypochlorite, and chlorhexidine have been suggested for disinfection of orthodontic appliances and removable prosthesis $[2,11,15,16]$. The choice of disinfectant should be made with regard to its effectiveness in inactivating microorganisms without any adverse effects on the materials [17] and human tissues [18].

In the last few years, chlorhexidine has been one of the most studied antimicrobial substances. It is considered 
the best choice among antiseptics for dental biofilm control, being effective for prevention of dental caries, gingivitis, and stomatitis [2,19-21]. Moreover, chlorhexidine gluconate has shown great efficacy in disinfection of toothbrushes [5,22], removable prosthesis [16-18,23], and removable orthodontic appliances [9]. However, no studies have addressed the effect/impact of chlorhexidine disinfection protocols for removable orthodontic appliances on the oral microbiota.

The purpose of this study was to assess the effect of chlorhexidine on plaque index and salivary levels of MS when used as the immersion solution for removable orthodontic appliances and added to their acrylic resin composition.

\section{MATERIAL AND METHODS}

This research project was approved by the local Research Ethics Committee, and written informed consent was obtained from parents or legal representatives. Fifteen patients of both genders aged from 6 to 12 years old, who had been referred to Preventive Orthodontic Clinic of the Faculty of Dentistry of Ribeirão Preto, University of São Paulo, for treatment with removable orthodontic appliances, were enrolled in this study. Patients, who were using antimicrobial mouthwashes, presented any systemic disease, had used antibiotics within the previous 3 months and with untreated caries lesions were excluded from the trial. By using a table of random numbers, the children were assigned to one of the 3 groups:

Group I: fifteen patients that did not make disinfection of orthodontic appliances, thus representing controls;

Group II: fifteen patients instructed to immerse their appliances into $0.12 \%$ chlorhexidine gluconate solution (Periogard, Colgate-Palmolive Ind. Brasileira, Osasco, SP, Brazil) overnight (8 hours), with solution being replaced every three days.

Group III: fifteen patients wearing removable orthodontic appliances made from acrylic resin with chlorhexidine gluconate.

Orthodontic appliances were constructed on cast models from each patient by using Hawley arch in the anterior region and drop-shaped hook in the posterior region, whereas baseplates were fabricated by using self-polymerising acrylic resin (Orto Class, Clássico Artigos Odontológicos Ltda, São Paulo, SP, Brazil) according to manufacturer's recommendations regarding monomer-topolymer ratio, standard acrylisation, trimming, and finishing/polishing techniques. The Group III baseplates were made with $14.4 \mathrm{~g}$ powder and $5.8 \mathrm{~g}$ liquid, including addition of $0.12 \mathrm{ml}$ of chlorhexidine digluconate solution at concentration of $20 \%$ (Natural Pharma, São João Clímaco, São Paulo, Brazil) to monomer, thus yielding acrylic resin with final concentration of $0.12 \%$ chlorhexidine. The amount of antimicrobial agent added to the acrylic resin was determined on the basis of their concentrations in mouth rinses largely used in dentistry clinic, that is, $0.12 \%$ chlorhexidine digluconate $[12,24]$. The patients were requested to wear the orthodontic appliances full time, except during sleep and meals. The children were instructed to brush their teeth using the Bass technique 4 times a day, and the parents or guardians were instructed to brush the orthodontic appliances once a day at bedtime by using the same toothbrush (Classic Infantil, Colgate-Palmolive Ind. Brasileira, Osasco, SP, Brazil) and fluoride-containing dental cream (Colgate, Colgate-Palmolive Ind. Brasileira, Osasco, SP, Brazil) received by each patient in the beginning of the study.

Saliva collection and plaque index were evaluated on 6 occasions: before the placement of orthodontic appliances and weeks 2, 4, 6, 8 and 10 following initial collection. Two $\mathrm{ml}$ of non-stimulated saliva were collected into properly labeled $15 \times 100 \mathrm{~mm}$ sterilised tubes containing 4 to 5 glass beads and then processed. Saliva samples were vortexed during 2.5 minutes for dispersion and then submitted to tenfold serial dilution. Next, $50 \mathrm{ml}$ of each dilution was plated equidistantly on modified $\mathrm{SB}_{20}$ culture medium and incubated under the candle-jar system at $37^{\circ} \mathrm{C}$ for 2 to 3 days. The modified $\mathrm{SB}_{20}$ culture medium, which is selective for MS, was prepared. Colonies/biofilms were evaluated by fermentation of mannitol, sorbitol, raffinose, and mellibiose; hydrolysis of arginine and sculin; production of hydrogen peroxide; and sensitivity to $2.0 \mathrm{IU}$ bacitracin $[25,26]$.

The plaque index score was obtained after saliva collection. Determination of plaque index and material collection for microbiological examination were performed at 9 - 10 a.m., that is, about 2 hours after breakfast.

\section{Statistical Analysis}

The original data, measured as colony forming unit (CFU), were transformed into log10 (CFU) for statistical analysis and expressed as log CFU. The results were analysed statistically by ANOVA and Tukey test by using GraphPad Prism ${ }^{\circledR}$ statistical software (GraphPad Software Inc., San Diego, CA, USA) at 5\% significance level.

\section{RESULTS}

Statistical analysis of the means of MS (log CFU) before treatment showed that the 3 groups were similar ( $p>$ 0.05). Evaluation of the number of MS (log cfu) in the saliva in the different phases of the study showed that there were no significant differences between the group I (control) and groups II and III $(p>0.05)$ or at the 6 collection times $(p>0.05)$ in each group. In other words, the quantity of MS (log CFU) in the saliva remains stable 
during treatment in 3 groups and that the amout of MS in the saliva at each collection time during treatment is similar to quantity before treatment in 3 groups. The means and standard deviation of mutans streptococci (log CFU) in saliva at each collection time are shown in Table 1.

Table 2 shows index plaque at each collection time according to studied groups. Analysis of the plaque index before orthodontic treatment by ANOVA showed that the 3 groups had similar mean values $(p>0.05)$. The plaque index was found to be statistically smaller at weeks 6,8 , and 10 in Group I (control) as well as at weeks 4, 6, 8, and 10 in Groups II and III compared to those values obtained before treatment. Although, the results showed no evidence of statistical difference between the three groups at each experimental period $(p>0.05)$, that is, there was no difference between the three groups.

\section{DISCUSSION}

Chlorhexidine has been employed as spray [9,27], as immersion solution $[11,17,18,28]$, or added to acrylic resin $[29,30]$ for disinfection of prosthesis and removable orthodontic appliances. In our experiment, we have used the immersion technique like others [31] and added chlorhexidine into the composition of acrylic resin. The statistical analysis showed that incorporation of chlorhexidine to acrylic resin of removable orthodontic appliances in a final concentration of $0.12 \%$ or immersion solution at $0.12 \%$ concentration for eight hours had no effect on amount of MS in saliva and plaque index during the orthodontic treatment. Studies of high and low concentrations of $\mathrm{CHX}$ have been reported to reduce the number of MS in plaque and saliva, and investigators have concluded that the use of $0.12 \%$ CHX mouth rinses could be beneficial for orthodontic patients in achieving improved oral hygiene. Evidence of the efficacy of CHX in biofilms was reported by Pratten et al. [32]. The literature suggests that the use of 1\% CHX gel significantly decreases MS levels [2,11,33]. Moreover, chlorhexidine used as the immersion solution did not induce adverse effects on acrylic resin at the concentration of $2 \%$ for 10 minutes [11] or at $4 \%$ for 7 days [17].

Advantages in adding chlorhexidine into the composition of acrylic resin of orthodontic appliance are that such approach does not depend on the patient's co-operation and is a method for extending the duration of effective chlorhexidine therapy [34,35]. Chlorhexidine diffuses out of acrylic resin in vivo at amounts sufficient to prevent or cure palatal candidosis for up to three weeks when mixed with acrylic powder in the proportion of $7.5 \%(w / w)$ [29].

Chlorhexidine can be added to acrylic resin as powder [31,34] or liquid [30]. Samples of acrylic resin containing chlorhexidine at the concentration of $4 \%$ incorporated at liquid form released the substance over a period of 72 days, with peak release observed in the first 20 days. Release from samples containing $1 \%$ and $2 \%$ chlorhexidine was observed for 10 days and was much lesser. The reason for this release pattern is probably due to the fact that chlorhexidine, under these circumstances, is a surface phenomenon [30]. Acrylic samples impregnated with chlorhexidine acetate at concentrations of $2 \%$, $5 \%$ and $10 \%$ by mixing polymer powder released chlorhexi- dine into water for more than 100 days [31]. However, the physical properties of the resins were compromised due to the presence of chlorhexidine particles,

Table 1. Means and standard deviations of mutans MS (log CFU) in saliva at each collection time according to studied groups.

\begin{tabular}{|c|c|c|c|c|c|c|c|c|c|c|c|c|}
\hline & \multicolumn{2}{|c|}{ Before treatment } & \multicolumn{2}{|c|}{2 weeks } & \multicolumn{2}{|c|}{4 weeks } & \multicolumn{2}{|c|}{6 weeks } & \multicolumn{2}{|c|}{8 weeks } & \multicolumn{2}{|c|}{10 weeks } \\
\hline & Mean & SD & Mean & SD & Mean & $\mathrm{SD}$ & Mean & $\mathrm{SD}$ & Mean & SD & Mean & $\mathrm{SD}$ \\
\hline Group I & 5.672 & 0.697 & 5.760 & 0.630 & 5.482 & 1.012 & 5.433 & 1.027 & 5.776 & 0.735 & 5.954 & 0.703 \\
\hline Group II & 5.007 & 1.226 & 5.300 & 2.066 & 5.302 & 1.705 & 5.381 & 1.717 & 5.494 & 1.003 & 5.440 & 1.040 \\
\hline Group III & 5.753 & 1.296 & 5.024 & 2.970 & 5.690 & 1.940 & 4.282 & 2.839 & 4.559 & 1.345 & 5.572 & 1.365 \\
\hline
\end{tabular}

$\mathrm{SD}=$ standard deviation.

Table 2. Means and standard deviations of dental plaque index values before and after installation of removable appliances according to each studied groups.

\begin{tabular}{|c|c|c|c|c|c|c|c|c|c|c|c|c|}
\hline & \multicolumn{2}{|c|}{ Before treatment } & \multicolumn{2}{|c|}{2 weeks } & \multicolumn{2}{|c|}{4 weeks } & \multicolumn{2}{|c|}{6 weeks } & \multicolumn{2}{|c|}{8 weeks } & \multicolumn{2}{|c|}{10 weeks } \\
\hline & Mean & SD & Mean & SD & Mean & SD & Mean & SD & Mean & SD & Mean & SD \\
\hline Group I & 0.958 & 0.029 & 0.744 & 0.253 & 0.692 & 0.145 & $0.566^{*}$ & 0.269 & $0.62^{*}$ & 0.225 & $0.63^{*}$ & 0.30 \\
\hline Group II & 0.928 & 0.072 & 0.758 & 0.403 & $0.540^{*}$ & 0.211 & $0.436^{*}$ & 0.227 & $0.42^{*}$ & 0.234 & $0.45^{*}$ & 0.25 \\
\hline Group III & 0.925 & 0.049 & 0.631 & 0.308 & $0.510^{*}$ & 0.348 & $0.333^{*}$ & 0.242 & $0.38^{*}$ & 0.259 & $0.32^{*}$ & 0.21 \\
\hline
\end{tabular}

$\mathrm{SD}=$ standard deviation; ${ }^{*}$ Statistically significant difference in relation to values obtained before the treatment at $p<0.05$. 
which then dissolved in the water and created porosity in the polymer matrix [31,34]. Therefore, in the present study, we added chlorhexidine to acrylic resin through the monomer to obtain samples containing the substance at the concentration of $0.12 \%$. Incorporation of chlorhexidine into the monomer caused no visible structural changes in the acrylic surface, as the same finishing and polishing characteristics seen in appliances made without chlorhexidine were also observed.

Chlorhexidine should be used in small amounts to avoid the adverse effect on the physical properties of acrylic resin and deleterious effects on the user of orthodontic appliance such as tooth stain, loss of taste, and loss of appetite [29]. The amount of chlorhexidine added to acrylic resin to obtain a final concentration of $0.12 \%$ was determined based on concentrations in formulations of mouth rinses commonly used in dentistry clinic [24, 36].

Rigour in controlling the levels of MS within the oral cavity of orthodontic patients is crucial for keeping their oral health, reducing the occurrence of caries lesions However, the use of $0.12 \%$ chlorhexidine as immersion solution and add to self polymerizing acrylic resin did not change the levels of MS in saliva and the plaque index, thus suggesting that these protocols to disinfection of removable orthodontic appliances at this concentration have no benefit in reducing the risk of caries in orthodontic patients.

Although the salivary levels of MS and the plaque index have no reduction through the use of chlorhexidine in this pilot study, this does not mean that disinfection of orthodontic appliances is not necessary. Controlling the microbial contamination of removable orthodontic appliances by means of disinfection is of crucial importance to preserve the patient's general health, since not only healthy patients are treated in the dentistry office, but also individuals with heart disease, diabetes mellitus, immunodeficiency and other systemic changes. These patients need additional care as there is always the possibility of occurrence of unwished bacteremia and infections. In addition, controlling microbial contamination of removable orthodontic appliances with strict disinfection measures is important to prevent inter-patient microbiological cross-contamination in the orthodontic setting [9].

The lack of difference between control group and the group that the chlorhexidine was added to acrylic resin can be attributed not only to the chlorhexidine concentration adopted in the present study, but also to the fact that the use of removable appliances depended on the patient's co-operation. On the other hand, for fixed orthodontic appliances whose structure contains acrylic resin (e.g. Hass expander), more effective microbial control and lower plaque index could be achieved.
Control of microorganisms on acrylic surface through immersion in disinfection solutions is well demonstrated in the literature, but incorporation of chlorhexidine into acrylic resin and its release into oral milieu require further investigation to verify the effectiveness of this method. In this way, it is necessary to perform both in vitro and in vivo studies using different concentrations of chlorhexidine added to acrylic resin in order to assess its effective antimicrobial action. A follow-up study with a larger study population is warranted to confirm the results of the present study and further studies with other antiseptic substances and methods of disinfection are also required.

Based on the results of this pilot study, it was concluded that incorporation of chlorhexidine into acrylic resin of removable orthodontic appliances at final concentration of $0.12 \%$ or immersion of such appliances into $0.12 \%$ chlorhexidine solution for eight hours was not effective in decreasing plaque index and amount of MS in saliva.

\section{REFERENCES}

[1] Batoni, G., Pardini, M., Giannotti, A., Ota, F., Giuca, M.R., Gabriele, M., et al. (2001) Effect of removable orthodontic appliances on oral colonisation by mutans streptococci in children. European Journal of Oral Sciences, 109, 388392. doi:10.1034/j.1600-0722.2001.00089.x

[2] Çatalbas, B., Ercan, E., erdemir, A., Gelgor, I.E. and Zorba, Y.O. (2009) Effects of different chlorhexidine formulations on shear bond strengths of orthodontic brackets. Angle Orthodontist, 79, 312-316.

doi:10.2319/032008-158.1

[3] Lundstrom, F. and Krasse, B. (1987) Streptococcus mutans and lactobacilli frequency in orthodontic patients; the effect of chlorhexidine treatments. European Journal of Orthodontics, 9, 109-116. doi:10.1093/ejo/9.1.109

[4] Leung, N.M., Chen, R., Rudney, J.D. (2006) Oral bacteria in plaque and invading buccal cells of young orthodontic patients. American Journal of Orthodontics and Dentofacial Orthopedics, 130, 698. doi:10.1016/j.ajodo.2006.05.028

[5] Nelson, F.P., Macari, S., Faria, G., Assed, S. and Ito, I.Y. (2000) Microbial contamination of toothbrushes and their decontamination. Pediatric Dentistry, 22, 381-384.

[6] Diedrich, P. (1989) Microbial colonization and various cleaning procedures for orthodontic appliances. Fortschr Kieferorthop, 50, 231-239. doi:10.1007/BF02168746

[7] Magno, A.F., Enoki, C., Ito, I.Y., Matsumoto, M.A., Faria, G. and Nelson-Filho, P. (2008) In-vivo evaluation of the contamination of Super Slick elastomeric rings by Streptococcus mutans in orthodontic patients. American Journal of Orthodontics and Dentofacial Orthopedics, 133, S104-S109. doi:10.1016/j.ajodo.2006.04.054

[8] Auschill, T.M., Hein, N., Hellwig, E., Follo, M., Sculean, A. and Arweiler, N.B. (2005) Effect of two antimicrobial agents on early in situ biofilm formation. Journal of Cli- 
nical Periodontology, 32, 147-152. doi:10.1111/j.1600-051X.2005.00650.x

[9] Lessa, F.C., Enoki, C., Ito, I.Y., Faria, G., Matsumoto, M.A. and Nelson-Filho, P. (2007) In-vivo evaluation of the bacterial contamination and disinfection of acrylic baseplates of removable orthodontic appliances. American Journal of Orthodontics and Dentofacial Orthopedics, 131, 705-707. doi:10.1016/j.ajodo.2006.09.042

[10] Sreenivasan, P.K., Mattai, J., Nabi, N., Xu, T. and Gaffar, A. (2004) A simple approach to examine early oral microbial biofilm formation and the effects of treatments. Oral Microbiology and Immunology, 19, 297-302. doi:10.1111/j.1399-302x.2004.00158.x

[11] da Silva, F.C., Kimpara, E.T., Mancini, M.N., Balducci, I., Jorge, A.O. and Koga-Ito, C.Y. (2008) Effectiveness of six different disinfectants on removing five microbial species and effects on the topographic characteristics of acrylic resin. Journal of Prosthodontics, 17, 627-633. doi:10.1111/j.1532-849X.2008.00358.X

[12] Kocak, M.M., Ozcan, S., Kocak, S., Topuz, O. and Erten, H. (2009) Comparisation of the efficacy of three dif- ferent mouthrinse solutions in decreasing the level of streptococcus mutans in saliva. European Journal of Dentistry, 3, 57-61.

[13] Jurela, A., Repic, D., Pejda, S., Juric, H., Vidakovic, R., Matic, I. and Bosnjak, A. (2013) The effect of two different bracket types on the salivary levels of $S$ mutans and $S$ sobrinus in the early phase of orthodontic treatment. The Angle Orthodontist, 83, 140-145. doi:10.2319/030612-187.1

[14] Jordan, C. and LeBlanc, D.J. (2002) Influences of orthodontic appliances on oral populations of mutans streptococci. Oral Microbiology and Immunology, 17, 65-71. doi:10.1046/j.0902-0055.2001.00083.x

[15] Denton, G.W. (1991) Chlorhexidine. In: Block, S.S., Ed., Disinfction, Sterization, Preservations, 4 Edition, Lea \& Fegiber, Philadelphia, 274-289.

[16] André, R.F., Andrade, I.M., Silva-Lovato, C.H., Paranhos Hde, F., Pimenta, F.C. and Ito, I.Y. (2011) Prevalence of mutans streptococci isolated from complete dentures and their susceptibility to mouthrinses. Brazilian Dental Journal, 22, 62-67.

[17] Azevedo, A., Machado, A.L., Vergani, C.E., Giampaolo, E.T., Pavarina, A.C. and Magnani, R. (2006) Effect of disinfectants on the hardness and roughness of reline acrylic resins. Journal of Prosthodontics, 15, 235-242. doi:10.1111/j.1532-849X.2006.00112.x

[18] Pavarina, A.C., Machado, A.L., Giampaolo, E.T. and Vergani, C.E. (2003) Effects of chemical disinfectants on the transverse strength of denture base acrylic resins. Journal of Oral Rehabilitation, 30, 1085-1089. doi:10.1046/j.1365-2842.2003.01150.x

[19] Bishara, S.E., Vonwald, L., Zamtua, J. and Damon, P.L. (1998) Effects of various methods of chlorhexidine application on shear bond strength. American Journal of Orthodontics and Dentofacial Orthopedics, 114, 150-153. doi:10.1053/od.1998.v114.a84780

[20] Cacciafesta, V., Sfondrini, M.F., Stifanelli, P., Scribante, A. and Klersy, C. (2006) Effect of chlorhexidine application on shear bond strength of brackets bonded with a resin-modified glass ionomer. American Journal of Orthodontics and Dentofacial Orthopedics, 129, 273-276. doi:10.1016/j.ajodo.2004.07.050

[21] George, A.M., Kalangi, S.K., Vasudevan, M. and Krishnaswamy, N.R. (2010) Chlorhexidine varnishes effectively inhibit Porphyromonas gingivalis and Streptococcus mutans-An in vivo study. Journal of Indian Society of Periodontology, 14, 178-180.

[22] Chamele, J., Bhat, C., Saraf, T., Jadhav, A., Beg, A., Jagtap, C., Ubeja, R. and Patil, P. (2012) Efficacy of microwaves and chlorhexidine for disinfection of pacifiers and toothbrushes: An in vitro study. Journal of Contemporary Dental Practice, 13, 690-694.

[23] Kulak, Y., Arikan, A., Albak, S., Okar, I. and Kazazoglu, E. (1997) Scanning electron microscopic examination of different cleaners: Surface contaminant removal from dentures. Journal of Oral Rehabilitation, 24, 209-215. doi:10.1111/j.1365-2842.1997.tb00315.x

[24] Ciancio, S.G. (1992)Agents for management of plaque and gingivitis. Journal of Dental Research, 71, 14501454. doi:10.1177/00220345920710071701

[25] Shklair, I.L. and Keene, H.J. (1974) A biochemical scheme for the separation of the five varieties of Streptococcus mutans. Archives of Oral Biology, 19, 1079-1081. doi:10.1016/0003-9969(74)90099-5

[26] Whittenbury, R. (1964) Hydrogen peroxide formation and catalase activity in the lactic acid bacteria. Journal of General Microbiology, 35, 13-26. doi:10.1099/00221287-35-1-13

[27] Peixoto, I.T., Enoki, C., Ito, I.Y., Matsumoto, M.A. and Nelson-Filho, P. (2011) Evaluation of home disinfection protocols for acrylic baseplates of removable orthodontic appliances: A randomized clinical investigation. American Journal of Orthodontics and Dentofacial Orthopedics, 140, 51-57.

[28] Morgan, T.D. and Wilson, M. (2000) Anti-adhesive and antibacterial properties of a proprietary denture cleanser. Journal of Applied Microbiology, 89, 617-623. doi:10.1046/j.1365-2672.2000.01158.x

[29] Lamb, D.J. and Martin, M.V. (1983) An in vitro and in vivo study of the effect of incorporation of chlorhexidine into autopolymerizing acrylic resin plates upon the growth of Candida albicans. Biomaterials, 4, 205-209. doi:10.1016/0142-9612(83)90012-1

[30] Wilson, S.J. and Wilson, H.J. (1993) The release of chlorhexidine from modified dental acrylic resin. Journal of Oral Rehabilitation, 20, 311-319. doi:10.1111/j.1365-2842.1993.tb01613.x

[31] Addy, M. (1981) In vitro studies into the use of denture base and soft liner materials as carries for drugs in the mouth. Journal of Oral Rehabilitation, 8, 131-142. doi:10.1111/j.1365-2842.1981.tb00486.x

[32] Sandham, H.J., Brown, J., Chan, K.H., Phillips, H.I., Burgess, R.C. and Stokl, A.J. (1991) Clinical trial in adults of an antimicrobial varnish for reducing mutans streptococci. Journal of Dental Research, 70, 1401-1408. doi:10.1177/00220345910700110201

[33] Beyth, N., Redlich, M., Harari, D., Friedman, M. and Steinberg, D. (2003) Effect of sustained-release chlorhe- 
xidine varnish on Streptococcus mutans and Actinomyces viscosus in orthodontic patients. American Journal of Orthodontics and Dentofacial Orthopedics, 123, 345-348. doi:10.1067/mod.2003.19

[34] Addy, M. and Handley, R. (1981) The effects of the incorporation of chlorhexidine acetate on some physical properties of polymerized and plasticized acrylics. Jour- nal of Oral Rehabilitation, 8, 155-163. doi:10.1111/j.1365-2842.1981.tb00488.x

[35] Douglas, W.H. (1977) Dental materials as carriers for therapy. Dental Update, 4, 395-399.

[36] Parfitt K. (1999) The complete drug reference. 32 Edition, Pharmaceutical Press, London. 